\title{
ESTÉTICAS EN LUCHA. LA SUBLIMIDAD DE LA PÉRDIDA EN LA NOVELA DE MI VIDA O EL REALISMO ESTÉTICO DE LEONARDO PADURA
}

\author{
POR \\ Claudia Hammerschmidt \\ Friedrich-Schiller-Universität Jena
}

Leonardo Padura es un autor de éxito mundial muy comprometido con la realidad socio-política e histórica de Cuba. Apreciado como excelente narrador al estilo de la novela decimonónica, innovador de estructuras novelísticas, autor posmoderno altamente intertextual e intermedial, se considera poco propenso al experimento lingüístico-formal, y por ende sin pretensiones de desarrollar una estética escrituraria que escenifique su disenso político desde el lenguaje mismo. A esta calificación casi de autor "light" contribuyen los géneros narrativos de los que se sirve Padura. Ya que este autor, que critica las perversiones de la era posrevolucionaria cubana desde La Habana sin haber tenido que exiliarse nunca, se dio a conocer con sus novelas neopoliciales sobre Cuba, ${ }^{1}$ en donde tematiza la actualidad política de la isla desde la perspectiva de Mario Conde y sobrepone realidad y ficción, reprobando la primera desde la segunda, en tramas que atrapan al gran público. Libros como su tetralogía Las cuatro estaciones (1991-1998), Adiós Hemingway (2001) o La neblina del ayer (2005) combinan la crítica políticasocial con la investigación de crímenes ficticios ubicados en La Habana de una época tan crucial para Cuba como lo fueron los años 1989 o 1958/59. Por estas razones sus textos, rebosantes de pasajes metafórico-descriptivos que escenifican el descontento de sus protagonistas a través de la acumulación de detalles "superfluos" creando intensos "efectos de realidad", se calificaron de esencialmente realistas. ${ }^{2} \mathrm{Y}$ podría mantenerse que a partir de La novela de mi vida (2002) - texto que con El hombre que amaba a los perros (2009) o Herejes (2013) abre una segunda serie de novelas-, Padura prosigue su modelo crítico-realista al servirse de lo que a partir de los años 70 se dio en llamar

\footnotetext{
' Al respecto de las novelas policiales o neopoliciales de Padura y su renovación del género, véase Braham, Oakley, Uxó y Wilkinson.

2 A esta calificación contribuyó el mismo Leonardo Padura al autocalificarse de "novelista realista": "Porque, si fuera necesario o posible definirme, caería dentro de lo que se solía (o se suele, ya no lo sé) considerar un escritor realista, en la medida en que el alimento proteico de todas mis novelas es la realidad: la vivida, la conocida, la estudiada [...]" ("La libertad" 12). Acerca de la noción de "efecto de realidad", véase todavía Barthes.
} 
"nueva novela histórica" latinoamericana. Ya que La novela de mi vida, tanto como sus novelas neopoliciales y conforme al género neohistórico, al confrontar la vida novelada del poeta romántico José María Heredia con la vida ficticia del expoeta y exprofesor universitario de letras cubanas, Fernando Terry, en una "superposición de tiempos históricos diferentes" (Aínsa, "La nueva novela histórica latinoamericana” 83), efectúa "una relectura de la historia" (Aínsa, "La nueva novela histórica latinoamericana" 84) que combina la insistencia en el "carácter cíclico de la historia" con la "ficcionalización de personajes históricos", la "metaficción [y la] intertextualidad" (Menton 42-43), para así dar "voz a lo que la historia ha negado, silenciado o perseguido" (Aínsa, "Nueva novela histórica y relativización” 12).

\section{HiPÓTESIS I}

Sin embargo, lo que me interesa analizar a continuación no es el realismo crítico de una escritura supuestamente "light", sino la complejidad de una escritura siempre doble en Padura. Así, concentrándome en La novela de mi vida, leeré su texto como puesta en escena de un realismo estético entre sublime y banal que se manifiesta como experiencia paradójica de la pérdida, ilustrada tanto en la constitución y muerte del autor como en el tema del exilio cubano. Sirviéndome del reparto de lo sensible como lo plantea Jacques Rancière, intentaré demostrar que es a través de la estructura quiástica entre dos estéticas en lucha que la novela propone una salida a la paradoja, tanto estética como existencial, implícita en la pérdida. Concluiré que, de esta manera, Padura ilustra autoría y exilio como causas y productos de un disenso tanto político y estético, y transforma su supuesto realismo no-experimental en un realismo estético y autorreflexivo. De esta manera, manifiesta una postura que va mucho más allá de un realismo tradicional o compromiso antiestético en la tradición de Sartre, ${ }^{3}$ desarrolla una escritura política que convierte la presunta unidimensionalidad de su narración en un palimpsesto donde las posiciones y voces constantemente se entrecruzan y contradicen, y logra proponer un nuevo realismo pos-experimental ${ }^{4}$ que ostenta su distancia de la realidad y ubica su escritura en el entre-lugar incómodo entre arte y vida. ${ }^{5}$

\footnotetext{
3 Que, en resumen, conceptualizó la "littérature engagée" como medio de reapropiación del mundo a través de su representación intencional basada en la explicación, no en el placer estético. Véase Sartre.

4 Entiendo "pos-experimental" en el sentido que se realiza a través de la experiencia y conciencia del experimento como había sido practicado por las vanguardias históricas y la "nueva novela latinoamericana". Véase al respecto Horne.

5 Véase al respecto el análisis de Amar Sánchez, Ana María. "El arte de la política/la política del arte" (24758), donde lee la novela El hombre que amaba a los perros tanto desde el enfoque del "acontecimiento" histórico definido por Alain Badiou como también desde la distancia estética del arte como la concibe Rancière ("Las paradojas del arte político"). Amar Sánchez llega a la conclusión que es en el sujeto narrador, "lugar privilegiado donde poner en escena, representar, la tensión entre política y textualidad"
}

$111 \frac{\text { Revista Iberoamericana, Vol. LXXXV, Núm. 269, Octubre-Diciembre 2019, }}{1205-1222}$ 
Ya la caracterización de los personajes principales de La novela de mi vida transforma el género histórico ${ }^{6}$ en metanovela: ${ }^{7}$ los protagonistas aquí ya no son representantes del poder estatal, conquistadores, libertadores o dictadores, sino - poetas. Y a pesar de que el libro de Padura nos proporciona un panorama socio-político de Cuba a partir del temprano siglo XIX hasta fines del siglo XX, y que se centra en el exilio como una de las constantes histórico-políticas del país, otro enfoque del libro es la constitución del autor moderno en su lucha política y estética por la autonomía de su país y de su escritura. ${ }^{8}$ Así, La novela de mi vida también pertenece a la tradición decimonónica de la novela del artista/autor cuya formación aquí se relaciona con la experiencia de lo sublime, la dialéctica de actividad y pasividad, presencia y ausencia o nacimiento y muerte del autor en Cuba. ${ }^{9}$

La novela-que consiste de dos partes, "El mar y los regresos" y "Los destierros", a su vez divididas en 59 subcapítulos sin denominación-obviamente se centra en el difícil tema cubano del exilio y retorno al dividirse en dos narraciones cuyas materialidades textuales y tramas ficcionales sobre el destierro y retorno constantemente se entrecruzan. ${ }^{10}$

(254), donde se sobreponen "referencia y autorreferencia" (253). En La novela de mi vida, sin embargo, y como veremos a lo largo de este análisis, los narradores no se fusionan, sino que se entrecruzan desde polos opuestos, formando así un quiasmo que, en la demonstración de su mutuo fracaso de expresar su disenso, logra transformarse en una estética en/de lucha.

6 De modo parecido, Padura había transformado el género policial, basado tradicionalmente en el desciframiento o lectura de los signos, al invertir esta tendencia y convertir a su protagonista, Mario Conde, en escritor fracasado que sueña con hacerse autor. Véase al respecto los estudios citados en nota 1.

7 Ver al respecto Janet Pérez, Laethem y Behar.

8 Así, la novela también se inscribe, invirtiéndola, en la larga tradición de la novela de formación, establecida a mitad del siglo XVIII y donde se cuenta de forma teleológica la vida del protagonista desde sus inicios inseguros hasta el desarrollo de su destino predeterminado. Véase al respecto Kontje y Jacobs.

9 Véase para la tradición de la novela del artista Garín Llombart, Felipe Vicente y Facundo Tomás Ferré, eds. En el país del arte, tomo III: La novela del artista. Valencia: Biblioteca Valenciana, 2003; para la teoría de la autoría moderna como incisión, como paradoja de la ganancia en la pérdida y viceversa, mi Autorschaft als Zäsur. Vom Agon zwischen Autor und Text bei d'Urfé, Rousseau und Proust. München: Fink, 2010.

${ }^{10}$ Para el tema de la representación narrativa del retorno a Cuba desde el exilio y la diáspora, véase el estudio de López, que brinda un vasto panorama del retorno vivido o ficcionalizado por la llamada "generación uno y media" (término acuñado por Gustavo Pérez Firmat en Life on the Hyphen, para caracterizar a los integrantes de la diáspora cubana que dejaron Cuba y llegaron a EE.UU. en la niñez o la adolescencia, experimentando un largo proceso de adaptación marcado por la biculturalidad y el bilingüismo), se concentra en su análisis de La novela de mi vida en la eterna nostalgia de los exiliados "unable or unwilling to imagine a home away from home" (218). Por consiguiente, insinúa la "nationalist ideology" de la novela, basada en la "superimposition of nationality and territory" (219), y

$111 \frac{\text { Revista Iberoamericana, Vol. LXXXV, Núm. 269, Octubre-Diciembre 2019, }}{1205-1222}$ 
La primera, con la que se abre el texto, cuenta en tercera persona la vuelta temporaria a La Habana del antiguo poeta e investigador universitario Fernando Terry, que se fue de Cuba en 1980 y que vuelve por un mes en 1998 para llevar a cabo la búsqueda de la autobiografía de José María Heredia a la que le sigue los pasos desde los años 70. La segunda se constituye por esta misma autobiografía ficticia de Heredia, "primer poeta nacional" según Martí, primer poeta cubano exiliado y primer poeta romántico latinoamericano que, según destaca Padura en un largo ensayo crítico sobre el poeta publicado un año después de su novela (“José María Heredia o la elección de la Patria"), no solo fue el primer cantor hispanohablante del paisaje americano que dio inicio a la literatura cubana, sino que incluso fue el inventor de la cubanía. ${ }^{11}$ Es, obviamente, esta segunda narración la que le da el título al libro entero ${ }^{12}$ y es la meta u objeto de deseo de la primera. ${ }^{13}$

habla de la escenificación de una "rooted form of cultural belonging": "The unhomely feelings of both Heredia and Terry after their return soon dissipate, and despite the vicissitudes of living under regimes with the potential of 'betraying ideals and the best of just causes' (Padura 125), the fictional characters stake a claim within the boundaries of the island. Despite the impediments, homeland eclipses diaspora" (218). Mi lectura de La novela de mi vida difiere bastante de este análisis, al proponer la existencia de una estética basada en la distancia en el texto de Padura. Sin embargo, agradezco a Iraida López el diálogo fructífero y el productivo intercambio de puntos de vista acerca de La novela de mi vida.

${ }^{11}$ Para el concepto de 'cubanía' y su crítica, especialmente en La novela de mi vida, véase Odette Casamayor: "Algo permanece inalterable para los personajes de La novela de mi vida, confrontados a los vertiginosos cambios sociales de la Cuba de fines de los noventa: es la comunidad espiritual de todos los cubanos, poco importa donde vivan; y la isla, el espacio que termina siempre por acoger, fértil terreno de una sensibilidad común" (151).

12 A su vez, como lo señalan los mismos epígrafes de las dos partes de la novela, este título es la cita del Heredia histórico que dos días después de su famosa visita al Niágara le preguntaba en una carta a su tío Ignacio: "Si mis ideas, como empiezo a temerlo, no son más que quimeras brillantes, hijas del acaloramiento de mi alma buena y sensible, ¿por qué no acabo de despertar de mi sueño? ¡Oh! ¿Cuándo acabará la novela de mi vida, para que empiece su realidad?" (“Carta del Niágara" 49). Desde el título, entonces, se entrecruzan historia y ficción en la novela de Padura.

${ }^{13}$ En mi análisis me concentro en la escritura de Padura como palimpsesto donde se superponen la realidad política del exilio y la experiencia de la falta como premisa para la constitución del autor, y en el disenso en su doble sentido de desacuerdo y distancia. No analizo el papel del personaje histórico José María Heredia como uno de los fundadores del discurso independentista de América Latina. Véase para este contexto Rojas, Las repúblicas de aire. Para la importancia del personaje histórico tanto para la política como para la poesía latinoamericana, véase también Ángel Esteban en este mismo dossier: "Cuba, punto de (des)encuentro de la cultura occidental en la narrativa de Leonardo Padura". También su breve análisis de la película que se hizo de la novela (y con el guion) de Padura, Regreso a Ítaca (dir. Laurent Cantet. Francia, 2014), película que reduce la complejidad de La novela de mi vida al regreso a La Habana de Fernando Terry (que aquí se hizo Amadeo). Agrego que esta película, salida de la novela, posteriormente se transformó en una versión novelizada de la película (Leonardo Padura y Laurent Cantet. Regreso a Ítaca. Buenos Aires: Tusquets, 2016), que incluye también un fragmento de La novela de mi vida. Así, Padura se acerca a la "maquinaria de la republicación" como había sido característica de Guillermo Cabrera Infante. Véase al respecto mi estudio "Mi genio es un enano llamado Walter Ego". 
No obstante, aunque la presencia misma y constante citación de la autobiografía ficticia de Heredia parece comprobar su existencia, en el nivel de la narración con la que se abre la novela y que presenta la búsqueda de Fernando por el texto hipotético del poeta cubano, "La novela de mi vida" se inscribe únicamente como falta o huella de algo que desde el inicio se perdió. ${ }^{14}$ Para comprobar intradiegéticamente la existencia de la autobiografía, se intercala entonces una tercera narración, ubicada principalmente en los años 20 y 30 del siglo pasado, y que presenta las reflexiones de los diversos detentores de los papeles autobiográficos acerca de las razones para conservar o hacer desaparecer "La novela de mi vida". ${ }^{15}$

Considerando este encadenamiento de las tres narraciones en un nivel metatextual, el tema del poeta, su exilio y su retorno transitorio se dobla entonces en el tema de la escritura: ${ }^{16}$ si la primera narración, la vuelta de Fernando, es la narración de la búsqueda de una escritura; y la segunda, la vida de Heredia, la narración del nacimiento de la misma; la tercera narración, focalizada en la Logia, presenta tanto la censura como la odisea de la escritura para llegar a su meta. ${ }^{17} \mathrm{Y}$ tanto como la autobiografía ficticia tan arduamente buscada nunca llega a su destinatario y deriva sin dirección predecible hasta desaparecer al final en las llamas destructoras, también su autor y lector se constituyen a partir de un abismo que se abre entre ellos por la ausencia del texto y por el exilio que los aísla de sus contextos acostumbrados. ${ }^{18}$

${ }^{14}$ Las historias de Heredia y de Fernando Terry solo se cruzan físicamente al final de la novela con la entrega a Fernando de una carta escrita por Heredia a través de Carmencita, última descendiente herediana y puente entre los dos protagonistas. Sin embargo, Fernando nunca encontrará su objeto del deseo, perseguido ya desde antes del exilio y ahora, en el presente de la narración, convertido en meta (frustrada) del viaje.

$15 \mathrm{Y}$ es esta tercera historia, que se inicia en 1921 con la entrega del manuscrito a la logia matancera Hijos de Cuba por el último hijo de José María Heredia, José de Jesús, y que se termina en 1939 con la quema de los papeles por Dominguito Vélez de la Riva, la que de alguna manera establece el efecto de realidad y el supuesto valor documental de "La novela de mi vida" o segunda narración, ya que no solo brinda la prueba intradiegética de la existencia de la autobiografía herediana buscada por Terry más allá de su deseo obsesivo, sino que explica el itinerario de los papeles, sigue sus huellas y pone en escena la importancia continuada que jugaron persistentemente en la política del país.

16 Esta, a su vez, se centra en los mecanismos de la invención, de la consolidación o de la destrucción de una tradición cultural y en los mecanismos de censura que la determinan.

17 Consideradas en su totalidad, las tres narraciones presentan entonces una versión novelesca de los principales factores implicados en la comunicación literaria que son la escritura, la lectura y el texto.

18 Son entidades imprecisas sin posiciones preestablecidas, que cambian de lugar y hasta trasgreden las fronteras entre ficción y realidad al convertir la vida en novela, como es el caso de Heredia, o la literatura en vida, como lo será el de Fernando. 


\section{VIDAS PARALELAS - ¿ALEGÓRICAS?}

Sin embargo, la interdependencia de la "novela" del poeta y su búsqueda por su lector va más allá del interés científico de Fernando Terry. Abundantes paralelismos entre las dos narraciones parecen sugerir una continuidad en espejo que une la vida contemporánea del investigador a la vida del poeta. Tanto Heredia como Terry son escritores exiliados que vuelven temporariamente a la isla para saldar cuentas pendientes y reencontrarse con un amor que dejaron atrás; tanto Heredia como Terry son víctimas de un régimen anti-democrático -monárquico-colonial en un caso, revolucionariocomunista en el otro- y son o se piensan víctimas de la traición por la antigua banda de amigos; tanto Heredia como Terry se deben reinventar, con más o menos éxito, una vez fuera de la isla de la que los dos sufren una incontenible nostalgia.

Son estos paralelos entre el poeta y su investigador los que indujeron a la crítica a hablar del alegorismo de La novela de mi vida. Mientras, por un lado, y siguiendo el tópico del espejismo referido por Antonio Benítez Rojo para caracterizar el Caribe (cfr. La isla que se repite), se subraya la repetitividad y circularidad de la novela donde -en palabras de Ángel Esteban- "los personajes individuales representan posturas de ciertos tipos humanos que se repiten. Heredia que se repite, la Historia que se repite, la Isla que se repite" (335); por el otro, se destaca el "realismo controlado" (Rojas, Tumbas 363 ) de Padura que, en el caso de La novela de mi vida, según Rafael Rojas "apela al recurso de la alegoría para narrar oblicuamente el presente político"19 (Tumbas 366) a través de "arquetipos históricos de una subjetividad nacional que se reitera" (Tumbas 368). En esta lectura -que llamaría alegórico-tipológica-, de alguna forma Heredia

19 Hay que señalar, sin embargo, que intradiegéticamente no son ni Heredia ni Fernando los que tratan de retratar la Cuba actual a través de una historia decimonónica, sino que es un personaje secundario, el Negro Miguel Ángel, el que recurre al tipo de representación justamente rechazada por Fernando: "Unos meses antes, Fernando había recibido lo que el Negro consideraba el primer borrador de su tercera novela, y leyó en vilo una historia decimonónica, de gentes comunes, que se encuentran y desencuentran movidos por los vientos de la historia, en una trama a través de la cual se podía hacer una lectura oblicua del presente cubano" (Novela de mi vida 41). Es el evidente fracaso de las aspiraciones pasadas el que hace rechazar esta forma de representación a Fernando: "La posibilidad de revisar, de golpe, sumariamente, el cúmulo de fidelidades, traiciones, mutaciones y consecuencias que van armando las vidas de las personas, le provocó a Fernando una amarga desazón: montar el pasado sobre el presente resultaba un ejercicio casi taimado, capaz de poner en molesta evidencia castraciones y abandonos imposibles de imaginar cuando el presente era el futuro, mientras el pasado resultaba ser algo tan breve que se resumía en dos palabras, en alguna herencia ambiental o genética, y en unas pocas actitudes asumidas" (41). El tema de la relación difícil entre los tiempos, el peligro que significa su comparación, se repite en el juego que propone Fernando a los Socarrones en octubre de 1974: "Pensando en todo esto que estamos hablando se me ocurrió que me encantaría mirar por un huequito el futuro, no sé, dentro de veinticinco años, y ver qué cosa va a haber hecho cada uno, qué va a ser cada uno...” (166). Al comparar las aspiraciones de los Socarrones en los 70 y su resultado en los 90, es obvio que la lectura del presente con el pasado o la imaginación del futuro desde el pasado solo lleva al fracaso. 
deviene la prefiguración de Terry y de toda esta larga serie de exilios cubanos que une la vida del "primer poeta cubano" del temprano siglo XIX con la Revolución cubana, el fin del siglo XX e incluso la contemporaneidad.

Esta línea interpretativa, sin embargo, ${ }^{20}$ no deja de incurrir en cierto esencialismo hermenéutico de la lógica representativa que nivela las diferencias funcionales y estéticas representadas por Heredia y Terry. Y a pesar de que el exilio es una constante tanto de la vida política cubana como de la literatura de Padura, ${ }^{21}$ considero que La novela de mi vida no escenifica simplemente la traumática experiencia del destierro como continuidad, destino o moira sin escapatoria. Todo al contrario, a pesar de que las vidas de Heredia y Terry ostentan los paralelos ya indicados -opiniones políticas disidentes, amores infelices, amigos sospechosos de una traición como causa de la catástrofe en la vida de los dos: el exilio-, ilustran al mismo tiempo los polos opuestos de una estética o experiencia de lo sensible que nace del exilio como pérdida de continuidad, condición y consecuencia de la autonomía tanto del sujeto social como de la escritura poética.

\section{HiPÓTESIS II}

Por consiguiente, propongo que La novela de mi vida pone en escena el exilio como origen de una estética basada en la sublimidad de la pérdida y como causa de un terror a la vez productivo y aniquilador, manifiesto en los distintos nacimientos y muertes de autores y lectores en la novela. ${ }^{22}$ Sugiero que en la literatura de Padura, el exilio se convierte en el punto de inflexión que redistribuye las coordenadas, refracta caminos, puede llegar a romper vidas -pero que, por la distancia que causa, también abre el camino a la reinvención-. Y como lo que denomino el "realismo estético" de la escritura de Padura se constituye en la superposición de las distintas modalidades estéticas practicadas por Heredia y Terry, me basaré para su ilustración en el concepto de los regímenes estéticos como los desarrolla Jacques Rancière a partir de los años 90.

\section{Políticas estéticas}

Como se sabe, en su enfoque de lo estético como reparto de lo sensible que subyace a la política, Rancière (véase Le Partage) diferencia tres regímenes diferentes: 1) el

${ }^{20}$ A pesar de toda la riqueza de los análisis que leen la literatura cubana según el parámetro de lo acuático (véase Esteban) o melancólico (véase Rojas, Tumbas).

${ }^{21}$ Véase al respecto mi artículo "La escritura como marca y máscara del significante ausente".

${ }^{22}$ Esta pérdida se pone en escena en toda su ambivalencia: como pérdida del lugar o destierro que se asemeja a la experiencia de lo inefable, como pérdida de ideales o inacción que nace de la desilusión política, y como pérdida de la palabra o silencio establecido a partir de la (auto)censura. En lo que sigue, me concentraré en el aspecto estético de la pérdida y dejaré para otra ocasión el estudio de la pérdida de ideales o de la palabra por la (auto)censura.

$111 \frac{\text { Revista Iberoamericana, Vol. LXXXV, Núm. 269, Octubre-Diciembre 2019, } 1205-1222}{\text { ISSN 0034-9631 (Impreso) }}$ 
régimen ético de las imágenes, un régimen normativo asociado con Platón y su pregunta por el estado ontológico de las imágenes, su condición de verdad o mentira y sus consecuencias para la comunidad; 2) el régimen representativo de las artes, asociado con Aristóteles y su concepto de mímesis, donde se juzga la capacidad creadora por la verosimilitud de su imitación, por la similitud o discrepancia de la obra artística con el modelo a imitar, y donde se diferencian las artes según su diferente poder mimético; y 3) el régimen estético, asociado con Friedrich Schiller, donde ya no se identifica el arte con su relación a la verdad o su modo específico de la representación, sino donde se concibe como experiencia estética-sensual específica. Esta experiencia estética provoca la suspensión del reparto de lo sensible y, de esta manera, posibilita la articulación del dissensus o desacuerdo con el reparto de lo sensible social y establecido. Ya que es en el régimen estético donde no solo se difuminan los límites entre las artes, sino también entre el arte y la vida, entre la idea activa y la materia pasiva, entre el pensamiento y el no-pensamiento:

Este ámbito sensible, sustraído a sus conexiones corrientes, contiene una potencia heterogénea, la potencia de un pensamiento que se ha convertido en algo extraño respecto de sí mismo: producto idéntico al no producto, saber transformado en no saber, logos idéntico a un pathos, intención de lo no intencional, etcétera. (Rancière, "Sobre los regímenes" 6-7)

Y es por esta simultaneidad de lo que parece excluirse que el régimen estético organiza una experiencia sensible diferente y adquiere relevancia política. Pone en escena el entrecruzamiento entre la autonomía del acto y la heteronomía de la materialidad pasiva y con esto lleva implícito la promesa de una nueva comunidad sensible en donde se realizará la emancipación al afirmarse la posibilidad de todos y cada uno de estar en el lugar del cual se le excluye y de hacer lo que no debe hacer. ${ }^{23}$

\section{ARTE MODESTO, ARTE SUBLIME}

Estos regímenes, sin embargo, y no obstante su sucesión histórica, no son totalmente exclusivos. Es sobre todo el régimen estético con su coexistencia de logos y pathos que tiende hacia su superación en lo ético. Como lo indica Rancière, es especialmente en el arte contemporáneo o "pos-utópico" donde la doble tendencia de lo estético se divide en dos manifestaciones diferentes que, cada una por separado, desemboca en lo ético: un "arte modesto", lúdico o soft de la contigüidad que rehúye la pretensión de transformar el mundo y se abstiene de "la afirmación de la singularidad de sus objetos"

${ }^{23}$ Véase al respecto Rancière, "Communistes sans communisme?" (236). También Hebekus, Uwe y Jan Völker.

$111 \frac{\text { Revista Iberoamericana, Vol. LXXXV, Núm. 269, Octubre-Diciembre 2019, } 1205-1222}{\text { ISSN 2154-4794 (Electrónico) }}$ 
("Políticas estéticas" 11), y un arte sublime o hard ${ }^{4}$ que impacta por su poder radical de evocar un "otro" presentado como heterogeneidad absoluta. Las dos facetas, soft y hard, coinciden en tender a la nivelación de la diferencia entre el arte y el mundo, a la negación de la autonomía del arte como había sido proclamada por Kant y al establecimiento de un lugar común donde la vida y el arte coexisten sin distancia, indistintamente. Y a pesar de que estas dos facetas del arte "pos-utópico" desde siempre calificaron el régimen estético y constituyeron en su misma ambivalencia el malaise esthétique que lo caracteriza a priori, es su separación en sendas vías opuestas la que niega la autonomía del arte, nivela la diferencia entre el arte y el mundo y anula las posibilidades políticas de desacuerdo del arte para constituir así su mismo pos-utopismo. En lo que sigue, intentaré demostrar cómo en la novela de Padura son Heredia y Terry los que, desde polos opuestos, aniquilan la distancia entre arte y mundo y destruyen así la potencia política de la estética. Por el contrario, la novela de Padura, al confrontarlos constantemente y señalar un cambio operado en Terry, evita los dos extremos de relacionar vida y obra y trabaja el disenso desde la novela misma, proponiendo un realismo estético que reinscribe la distancia entre realidad y ficción y recupera así su autonomía.

\section{Sublimidad y modestia o el QUiaSmo estético Heredia/Terry}

Partiendo del concepto del exilio como origen de una estética basada en la sublimidad de la pérdida, en La novela de mi vida de Padura se pueden distinguir las dos facetas inherentes al régimen estético que Rancière destaca en el arte pos-utópico. Y a pesar de que la estética sublime del Heredia histórico marca el inicio de la autonomía del arte en la literatura latinoamericana justamente a través de la experiencia de lo sublime, ${ }^{25}$ en su presentación desde el siglo XXI, como objeto del deseo de su lector Fernando Terry, se subraya su tendencia hacia la disolución en lo ético de la que solo lo salvará la reinvención de Fernando al final del libro en su promesa de un nuevo dissensus y nuevo reparto de lo sensible más allá de la pérdida.

24 Para las denominaciones soft y hard, véase el último capítulo de Malaise dans l'esthétique, "Le tournant éthique de l'esthétique et de la politique". También During.

${ }_{25}$ Como lo destaca Heredia en su oda al Niágara (junio de 1824), es el terror experimentado por el sujeto aislado frente a la fuerza sobrehumana de la naturaleza el que le permite al yo fragmentado entrar en presencia de una revelación transcendente que al mismo tiempo lo aniquila y salva, haciéndole sentir a la vez su debilidad mortal y su magnitud moral eterna. Como se verá en adelante, tanto el poema de Heredia como su tematización en la novela de Padura refieren casi explícitamente a la teoría de lo sublime desarrollada por Burke (A Philosophical Enquiry) y Kant (Kritik der Urteilskraft), especialmente al análisis kantiano de lo sublime como lugar del 'disenso' entre lo finito e infinito, lo sensual y conceptual, lo natural y moral. Para un análisis de Heredia como primer poeta moderno en Latinoamérica que desarrolla una estética de lo sublime, véanse Altenberg, Beaupied y McVay. 
Las estéticas de Heredia y de Fernando, contrariamente al tópico de su relación alegórica, entonces no solo no se repiten, sino que proceden de manera casi quiástica, se enfrentan desde perspectivas temporales opuestas y desembocan en conceptos escriturarios heterogéneos, donde la escritura en voz propia, exclusiva, intensiva, intransitiva, se transforma en la narración del otro, inclusiva, extensiva, que insinúa, al final, un futuro.

Por un lado, la narración autobiográfica de Heredia procede retrospectivamente desde la desilusión (que ya en este caso podría llamarse pos-utópica). ${ }^{26}$ Presenta una estética-ya pasada en el momento de su presentación-que, vista prolépticamente desde el exilio político sufrido por la participación en la conspiración para la independencia de Cuba, se basa en la sublimidad de la pérdida, la distancia y ruptura con lo cercano. ${ }^{27}$ Esta estética, presentada analépticamente, desde la ruptura definitiva o catástrofe provocada por el exilio, y ya llevada al fracaso en el momento de la narración, a su vez se basa en un disenso y pone en escena tanto la invención de la naturaleza americana a través del terror como la invención del sujeto poético como autor que se constituye al aniquilarse en el mismo acto creador:

Me detuve y por algunos minutos me fue imposible distinguir mis propias sensaciones en medio de la estupefacción causada por el sublime panorama. El caudaloso río pasaba rugiendo y, casi a mis pies, se despeñaba desde una altura prodigiosa [...]. La mano misma del Creador tenía que estar detrás de aquella obra prodigiosa, tan diferente de otras que, por diversos motivos, habían calado en mi corazón. Pero aquí todo era fuerza desatada, pasión sin límites, muerte segura, a la vez que explosión de una belleza sublime, dotada del poder de sacar de su tumba a mis pensamientos y centrarlos en lo que le remitían mis pupilas. (Novela de mi vida 199)

Por el otro lado, Fernando, desde un exilio sufrido casi por error, por la supuesta traición de uno de sus amigos que después se evidenciará inexistente, no se constituye como autor, sino que se aniquila en la misma pérdida ocasionada por el exilio. Su concepto de la poesía, basado en la contigüidad, cotidianidad e inclusión del otro, lo lleva al fracaso como poeta en el momento de su distanciamiento de Cuba. Su salida de la isla (ocurrida dieciocho años antes del tiempo básico de la narración, que se abre en 1998 con su vuelta temporaria a La Habana) significó su práctica de olvido voluntario y su silencio poético, el cual solo se rompe en el presente de la narración al momento

${ }^{26} \mathrm{O}$ incluso fantasmal, pos-mortal, basada en un "yo" siempre posterior a su autor y signo prefigurador de su muerte. Véase al respecto de Man.

27 Aquí, frente al Niágara y conforme al famoso estudio de Edmund Burke (A Philosophical Enquiry into the Origin of Our Ideas of the Sublime and Beautiful), lo sublime actúa de manera paradójica como terror placentero y pérdida del yo que lleva a su (re)constitución. Véanse al respecto Hipple y Wood. 
de su reinvención como lector en la búsqueda del manuscrito de Heredia, que a su vez proyecta una posible vuelta a la escritura y a la vida:

En este momento Fernando Terry sintió la explosión y vio cómo el mundo se deshacía. Ninguna información podía ser más catastrófica y cruel que aquélla, ni siquiera la noticia de que la perseguida novela de Heredia fuera un sueño inalcanzable. La certeza de que en lugar de replegarse él debió haber luchado, lo enfrentaba a una posibilidad lamentable [...]. Y la evidencia de que el amor se le había escurrido entre los dedos lo hizo sentir la magnitud de una equivocación capaz de vaciar al universo de todo su sentido. (Novela de mi vida 62)

Y mientras que en el caso de Heredia se presentan las consecuencias de la estética de la pérdida, de un concepto del arte sublime y hard, para la formación del artista, que van desde la creación activa y entusiasta hasta el mutismo pasivo frente al reparto de lo sensible establecido al que se entrega sin defensa; ${ }^{28}$ en el caso de Fernando se presentan las consecuencias de esta misma estética en su forma modesta o soft: primero como negación que desemboca en la nada (silencio, olvido) y después como reconstrucción en la búsqueda de la escritura de "la novela de mi vida" de otro. Ésta, a pesar de que jamás se encuentre, lo llevará a descubrir la ficción de su propia vida de la que logrará salir con las últimas palabras pronunciadas en el texto, que indican la formación de una estética como disenso o distancia que se mantenga suspendida entre lo sublime y lo contiguo, el arte y la vida.

\section{El arte sublime de Heredia, o de la estética A la ÉticA}

La estética sublime de Heredia nace de la afirmación del espacio estético propio y autónomo del arte que -podría decirse desde Rancière- se manifiesta a través de "l'efficacité d'une distance"29 ("Les Paradoxes" 62) que posibilita "l'efficacité d'un dissensus" (66). Por un lado, antes del exilio, Heredia muy conscientemente se inventa

28 “[A]penas me aparté de la piedra la vi desprenderse y rodar al abismo: aquella piedra, sobre la cual había imaginado mi muerte y sentido mi resurrección, había caído donde ya no volverían a hollarla pies humanos y enfrióse de repente mi corazón, al comprender otra vez la debilidad de la línea que separa la vida de la muerte y la pequeñez de la voluntad humana ante los designios de Dios" (Novela de mi vida 201).

29 Véase también "l'efficacité de la suspensión de tout rapport direct entre la production des formes de l'art et la production d'un effet déterminé sur un public déterminé" ("Les Paradoxes" 64).

$111 \frac{\text { Revista Iberoamericana, Vol. LXXXV, Núm. 269, Octubre-Diciembre 2019, }}{1205-1222}$ 
como autor $^{30}$ al elegir su musa (la amante) ${ }^{31}$ y el objeto de su escritura (Cuba) $)^{32}$ y se constituye como sujeto poético romántico al reflejarse en su producto poético. ${ }^{33}$ Por el otro, es recién desde la distancia del exilio que tanto musa como objeto se convierten en espejos del abismo que separan al poeta de lo que canta ${ }^{34}$ y que provocan la irrupción de la experiencia de la distancia como pérdida sublime de la que nace la experiencia estética misma. Así, frente al Niágara, “todo era fuerza desatada, pasión sin límites, muerte segura, a la vez que explosión de una belleza sublime [...]. Por momentos sentí como mi cuerpo se vaciaba y mi espíritu flotaba fuera de sus límites físicos, libre y alborozado, ajeno a mi carne yerta, abandonada sobre una piedra húmeda, como restos de un muñeco inservible" (Novela de mi vida 199). Esta sensación de entrega pasiva a un poder inalcanzable tanto física como racionalmente, provoca al mismo tiempo la sensación de impotencia y la elevación hacia un más allá trascendente. En esta experiencia de lo sublimemente terrorífico se abre entonces el abismo que propulsa el sujeto a su disolución y lo afirma en el mismo acto de su reflexión, manifiesto en la estética de su escritura. Sin embargo, esta simultaneidad de actividad y pasividad,

30 En la retrospectiva, su invención en los años 1817 a 1819 se retrata así: "Mientras repaso mi existencia, aquellos dos años que pasé en Cuba, pleno y despreocupado, febril y lujurioso, parecen vividos por una persona ajena, a la cual apenas reconozco. Tenía quince años y di placer a mi cuerpo y libertad a mi mente, nada me torturaba y creí ser el hombre más feliz de la tierra. Pero, como es sabido, un poeta nunca debe tener derecho al goce pleno de su fortuna, y luego de pensarlo un poco me pareció llegado el momento de crearme un sufrimiento, y ninguno podía resultar más apropiado que un amor imposible" (Novela de mi vida 43-44).

31 "Y decidí, en ese preciso momento de placer, convertirme en un poeta desdichado en amores. Sólo me faltaba encontrar el blanco de mi amor imposible" (Novela de mi vida 45). Y poco después, el 16 de marzo de 1818, al conocer a Isabel Rueda y Ponce de León: "decidí convertirla en el objeto de mi amor. Tenía ella apenas doce años, pero como mi pasión iba a ser obviamente platónica, nadie podría acusarme de pervertido [...]. Desde ese día Isabel Rueda y Ponce de León se convertiría en el amor imposible alojado en el corazón del desgraciado poeta" (46).

32 "Para escribir poesías prefería sentarme en cualquiera de las plazas y paseos de la ciudad. La ebullición que se respiraba en la calle me servía de estímulo, y fue por esos días de exaltada juventud cuando también empecé a fraguar otra de mis decisiones trascendentales: si me era posible, escogería Cuba como mi patria poética, pues aquel país oprimido y corrupto, vital y generoso, tenía los encantos necesarios para que un poeta diera rienda suelta a su creatividad. Aquí la gente vivía a la espera de algo que nadie sabía lo que podía ser, pues había tantos partidarios como enemigos de la independencia, tantos que bailaban de júbilo con la apertura de los puertos al comercio como los que anunciaban la ruina económica que traería la medida, tantos los constitucionalistas como los monárquicos, tantos los que querían irse como los que deseaban quedarse... Pero, curiosamente, entre esos especímenes de todo lo imaginable no había un solo poeta que pudiera calificarse de tal: entonces, con la pasión poética que bullía en mí, no iba a ser difícil ascender al trono de un parnaso despoblado, que incluso yo podría decorar a mi antojo" (Novela de mi vida 45-46).

${ }^{33}$ Se podría decir -de acuerdo a Rancière- que supera, entonces, la estética representativa por crear lo que se representa en el mismo acto de su representación.

34 Véase sobre todo "Himno del desterrado" (1825), reproducido en la antología publicada por Padura en 2003 (José María Heredia. La patria y la vida).

$111 \frac{\text { Revista Iberoamericana, Vol. LXXXV, Núm. 269, Octubre-Diciembre 2019, }}{1205-1222}$ 
logos y pathos, se ve amenazada por la pérdida misma que la causa. En el caso de Heredia desemboca en su entrega a un poder heterogéneo que lo llevará al silencio de los últimos años vividos fuera de Cuba. Su estética se volverá ética al referirse más y más a "la novela de [su] vida", de la que para él no habrá salida. ${ }^{35}$

\section{El arte modesto de Fernando Terry, o de la ÉTICA A la estética}

Fernando tomará el camino inverso: dentro de la escenificación de las poéticas politizadas de sus amigos los "Socarrones" en 1974 donde se discuten la función y el deber de la literatura, ${ }^{36}$ Fernando toma una posición ética al pretender la relación de continuidad entre las formas sensibles de la producción artística y las formas sensibles de su recepción. ${ }^{37}$ Adhiere a una escritura "modesta", soft, al disminuir la distancia entre la vida y su arte que debe versar sobre historias mínimas, "sobre la gente, sobre la esperanza y la desesperanza..." (Novela de mi vida 164): "Yo escribo poesía y lo que me interesa es la gente, si sufre o si se enamora, si tiene miedo de morirse o si le gusta el mar" (163). Así, la estética de Fernando tiende hacia su disolución en el régimen ético por su misma simpatía hacia lo humilde, marginal o nimio - por lo que ya durante su vida en la isla no escribía mucho- $-{ }^{38}$ Desde su exilio, sin embargo, por la pérdida sufrida, esta simpatía se pierde. Fernando se instala en la distancia abierta entre él y las formas sensibles para llegar a negarlas en un olvido y silencio que aniquilan al autor. Recién de vuelta en Cuba, en 1998, al descubrir su falsa lectura pasada de los signos de amor, amistad y traición, vuelve a pensar posible su retorno a la escritura. Recién ahora logra distinguir entre su vida y la mentira, descubre su cautividad en una novela que no era la suya y cuyo texto quedará perdido para siempre. Es así que, en el único capítulo narrado en presente y que cuenta los últimos momentos antes de su debida vuelta a Madrid -después de su renuncia a encontrar jamás "la novela de mi vida" de

35 "Sé que es una actitud malsana cultivar de ese modo la nostalgia, pero únicamente aquellas referencias me mantenían cerca de una pertenencia a la que no quería renunciar. Quizá fue ése el gran error de mi existencia, o quizá todo fue así porque yo era incapaz de ser de otro modo y estaba predestinado a inventar el destierro de Cuba, la nostalgia por Cuba, el sueño de la libertad de Cuba, pero en cualquier caso hoy asumo esa forma de vida como la motivación principal que me mantuvo en la brega y me hizo ser el hombre que soy, y no otro, definitivamente distinto" (Novela de mi vida 268).

36 Véase el "banquete" de los amigos el 23 de octubre de 1974 y, sobre el trasfondo del realismo socialista proclamado en la Cuba posrevolucionaria, sus debates sobre el escritor como consciencia crítica de la sociedad, sobre la función política de la literatura, o también sobre el papel de la censura en la literatura (Novela de mi vida 162-67).

37 Véase Jacques Rancière: "une relation de continuité entre les formes sensibles de la production artistique et les formes sensibles selon lesquelles les sentiments et pensées de ceux et celles qui les reçoivent se trouvent affectés" ("Les Paradoxes" 58).

38 "Entre las reuniones y el trabajo de curso sobre Heredia, casi no he podido escribir... Aquí el único que no para es Enrique" (Novela de mi vida 166).

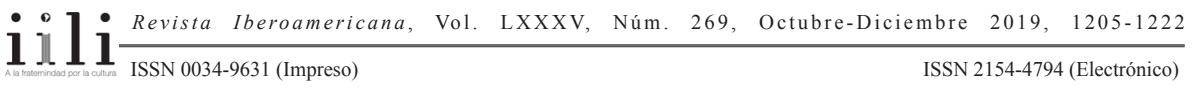


Heredia- ${ }^{39}$ Fernando acabará por realizar la autonomía del arte en su vida misma al proferir, en las últimas palabras de la novela de Padura, la promesa de un disenso futuro:

¿Es posible rebelarse?, se pregunta después, ya por pura retórica, sólo para abrir más la herida, pues sabe que el acto de la rebeldía es el primero que les ha sido negado, radicalmente extirpado de todas sus posibilidades y anhelos. Sólo le queda cumplir su moira, como Ulises enfrentó la suya, aun a su pesar; o como Heredia asumió la suya, hasta el final.

-Sí..., pero es que ahora no sé cómo irme -apenas consigue decir Fernando y, como tantas otras veces, es férreamente obligado a beber el primer sorbo de su café. (Novela de mi vida 342)

\section{La novela de mi vida, o el Realismo estético de Leonardo Padura}

Con estas últimas palabras de Fernando (que con el tema del café remiten al inicio del texto y a la llegada de Fernando a La Habana), la novela instala el dissensus como fin que es un comienzo y el centro mismo de la escritura política de Padura. Desde este dissensus -enunciado en el umbral del texto, en su final que se vuelve principio y traspasa así la frontera entre tiempos y lugares, adentro y afuera, novela y vida, y ubicando entre ellos el exilio, la distancia desde la que se narra-, el autor cubano instalado en La Habana cuestiona el reparto de lo sensible, impugna los lugares comunes y se rebela contra la repetición de lo mismo como moira. Al componer una novela como cruce entre realidad y ficción, que combina la nueva novela histórica con la novela del artista/autor que se construye y aniquila a partir de la experiencia de la pérdida y el exilio, La novela de mi vida redistribuye los argumentos, los hace cruzar de lado y entrecruzarse en forma quiástica, para poner en escena las paradojas de la pérdida desde la lógica del régimen estético mismo y volver a otorgarle a la palabra su poder de disenso. Al basarse en el fracaso del lugar común y poniendo en escena un continuo fuera-de-lugar - tanto de Heredia en cuanto representante de un arte sublime o hard como de Terry en cuanto representante de un arte modesto o soft-, la novela de Padura propone una escritura política palimpséstica, donde las posiciones y voces constantemente se entrecruzan y contradicen y donde el código es siempre por lo menos doble. Así, elabora un realismo estético pos-experimental que ostenta su distancia de la realidad y ubica su escritura en el entre-lugar incómodo entre arte y vida en el que se hace posible una redistribución de lo sensible. El final abierto de La novela de mi

${ }^{39}$ Véase también la lectura, poco antes de la partida, no de "la novela de mi vida" de Heredia, sino de la novela del amigo muerto Enrique: "Las escenas de la novela teatral comenzaron a pintar ante sus ojos una fábula premonitoria, llena de ironía y tristeza, dotada del poder clarificador de ir sustrayéndole años a la pretendida realidad de la vida para vaciarlos en una realidad de novela en la cual volvían a tener veinte años" (Novela de mi vida 341). 
vida, como posibilidad de un recomienzo que se mantiene indeciso entre la pérdida sublime y la vuelta a una cotidianidad compartida, deja abierta también la potencialidad de disenso de una literatura comprometida estéticamente, que insinúa la inminencia, siempre suspendida, de la rebeldía de sus estéticas en/de lucha.

\section{BiBLIOGRAFÍA}

Aínsa, Fernando. “La nueva novela histórica latinoamericana". Plural 240(1991): 82-85. "Nueva novela histórica y relativización del saber historiográfico". Casa de las Américas 202 (1996): 9-18.

Altenberg, Tilmann. Melancolía en la poesía de José María Heredia. Frankfurt a. M.-Madrid: Vervuert-Iberoamericana, 2001.

Amar Sánchez, Ana María. "El arte de la política/la política del arte: Semprún y Padura ante el asesinato de Trotzky". Cuadernos de Literatura XVIII/35 (2014): 247-58.

Badiou, Alain. L'Éthique. Essai sur la conscience du mal. Caen: Nous, 2003.

Barthes, Roland. "L'effet réel”. Communications 11 (1968): 84-89.

Beaupied, Aísa M. "Lo bello y lo sublime en dos poemas de José María Heredia". Revista de Estudios Hispánicos 31/1 (1997): 3-23.

Behar, Sonia. "Perspectivismo y ficción en La novela de mi vida. La historia como versión de sí misma". Memoria histórica, género e interdisciplinariedad. Los estudios culturales hispánicos en el siglo XXI. Santiago Juan Navarro y Joan Torres-Pou, eds. Madrid: Biblioteca Nueva, 2008. 23-29.

Benítez Rojo, Antonio. La isla que se repite: el Caribe y la perspectiva posmoderna. Hanover: Ediciones Del Norte, 1989.

Braham, Persephone. Crimes Against the State, Crimes Against Persons: Detective Fiction in Cuba and Mexico. Minneapolis: U of Minneapolis P, 2004.

Burke, Edmund. A Philosophical Enquiry into the Origin of Our Ideas of the Sublime and Beautiful. 1757. Nueva York: Bartleby.Com, 2001.

Casamayor, Odette. Utopía, distopía e ingravidez: reconfiguraciones cosmológicas en la narrativa post-soviética cubana. Frankfurta. M.-Madrid: Vervuert-Iberoamericana, 2013.

During, Elie. “Le Malaise esthétique.” Art Press 306 (nov. 2004). Republicado por el Centre International d'Étude de la Philosophie Française Contemporaine. <www. ciepfc.fr>. 8 de junio de 2014.

Esteban, Ángel. "Heredia que se repite: la isla y los tiranos". Literatura cubana entre el viejo y el mar. Granada: Renacimiento, 2006. 316-35.

Garín Llombart, Felipe Vicente y Facundo Tomás Ferré, eds. En el país del arte, tomo III: La novela del artista. Valencia: Biblioteca Valenciana, 2003.

Hammerschmidt, Claudia. Autorschaft als Zäsur. Vom Agon zwischen Autor und Text bei d'Urfé, Rousseau und Proust. München: Fink, 2010.

$111 \frac{\text { Revista Iberoamericana, Vol. LXXXV, Núm. 269, Octubre-Diciembre 2019, } 1205-1222}{\text { ISSN 2154-4794 (Electrónico) }}$ 
"La escritura como marca y máscara del significante ausente: Leonardo Padura y la visible ausencia de Guillermo Cabrera Infante". Hispanic Review 82/3 (2014): 359-76.

“Mi genio es un enano llamado Walter Ego”. Estrategias de autoría en Guillermo Cabrera Infante. Madrid: Iberoamericana, 2015.

Hebekus, Uwe y Jan Völker. Neue Philosophien des Politischen. Hamburg: Junius, 2012. Heredia, José María. "Carta del Niágara” (17 de junio de 1834). José María Heredia and "Niagara Falls". Keith Ellis, ed. La Habana: José Martí, 2010. 45-57.

"Himno del desterrado" (1825). José María Heredia. La patria y la vida. Leonardo Padura Fuentes. La Habana: Unión 2003. 142-46.

"Niágara" (1824). José María Heredia. La patria y la vida. Leonardo Padura Fuentes. La Habana: Unión, 2003. 136-41.

Hipple, Walter J. The Beautiful, the Sublime and the Picturesque in 18th-Cerntury British Aesthetic Theory. Carbondale: The Southern Illinois UP, 1957.

Horne, Luz. Literaturas reales. Transformaciones del realismo en la narrativa latinoamericana contemporánea. Rosario: Beatriz Viterbo, 2011.

Jacobs, Jürgen. Zwischenbilanzen des Lebens. Zu einem Grundmuster des Bildungsromans. Bielefeld: Aisthesis, 2005.

Kant, Immanuel. Kritik der Urteilskraft. 1790. Werkausgabe in zwölf Bänden. Band 10. W. Weischedel, ed. Frankfurt a. M.: Suhrkamp, 1974.

Kontje, Todd. Private Lives in the Public Sphere. The German Bildungsroman as Metafiction. University Park: Pennsylvania State UP, 1992.

Laethem, Merel. Historia, ficción y metaficción en La novela de mi vida de Leonardo Padura Fuentes. Gent: Universiteit Gent, 2007.

López, Iraida. Impossible Returns: Narratives of the Cuban Diaspora. Gainesville: UP of Florida, 2015.

Man, Paul de. "Autobiography As De-Facement." The Rhetoric of Romanticism. Nueva York: Columbia UP, 1984. 67-81.

McVay, Ted E. "The SublimeAesthetic in the Poetry of José María Heredia." Dieciocho. Hispanic Enlightenment 17/1 (1994): 33-41.

Menton, Seymour. La nueva novela histórica de la América Latina, 1979-1992. México: Fondo de Cultura Económica, 1993.

Oakley, Helen. From Revolution to Migration: A Study of Contemporary Cuban and Cuban-American Fiction. Oxford: Peter Lang, 2012.

Padura Fuentes, Leonardo. José María Heredia. La patria y la vida. La Habana: Unión, 2003.

“José María Heredia o la elección de la Patria". José María Heredia. La patria y la vida. La Habana: Unión, 2003. 7-53. 
"La libertad como herejía (Para qué se escribe una novela)." $<$ https://cri.fiu.edu/ news/2014/liberty-as-heresy-why-one-writes-novel-lecture-by-leonardo-padura/ la-libertad-como-herejia.pdf>. 1-29. 28 abril 2016.

La novela de mi vida. Barcelona: Tusquets, 2002.

y Laurent Cantet. Regreso a Ítaca. Buenos Aires: Tusquets, 2016.

Pérez, Janet. "Leonardo Padura Fuentes, La novela de mi vida. Academic detecting and the 'Novela Negra'." Hispanófila 143 (2005): 111-20.

Pérez Firmat, Gustavo. Life on the Hyphen: The Cuban-American Way. Austin: The U of Texas P, 1994.

Rancière, Jacques. "Communistes sans communisme?" L'Idée du communism. Alain Badiou y Slavoj Žižek, eds. Paris: Lignes, 2010. 231-45.

"Les Paradoxes de l'art politique". Le spectateur émancipé. París: La Fabrique, 2008. 56-92.

Le Partage du sensible: Esthétique et politique. París: La Fabrique, 2000.

"Políticas estéticas". Sobre políticas estéticas. Gerard Vilar, ed. y Manuel Arranz, trad. Barcelona: Museu d'Art Contemporani de Barcelona-Servei de Publicacions de la Universitat Autónoma de Barcelona, 2005. 9-32.

"Sobre los regímenes del arte y el escaso interés del concepto de modernidad".

La división de lo sensible. Estética y política. Antonio Fernández Lera, trad. Diciembre 2009. <http://poderesunidosstudio.files.wordpress.com/2009/12/ jacques-ranciere-la-division-de-lo-sensible1.pdf>. 10 junio 2014.

"Le tournantéthique de l'esthétique et de la politique".Malaise dans l'esthétique. Paris: Galilée, 2004. 143-173.

Retorno a Itaca. Dir. Laurent Cantet. Francia, 2014.

Rojas, Rafael. Las repúblicas de aire. Utopía y desencanto en la revolución de Hispanoamérica. México: Taurus, 2009.

Tumbas sin sosiego. Revolución, disidencia y exilio del intelectual cubano. Barcelona: Anagrama, 2006.

Sartre, Jean-Paul. Qu'est-ce que la littérature? París: Gallimard, 1948.

Uxó, Carlos, ed. The Detective Fiction of Leonardo Padura Fuentes. Manchester: Manchester Metropolitan UP, 2006.

Wilkinson, Stephen. Detective Fiction in Cuban Society and Culture. Oxford: Peter Lang, 2006.

Wood, Theodore E. B. The Word 'Sublime' and its Context (1650-1760). The HagueParis: Mouton, 1972. 
Palabras clave: Leonardo Padura - La novela de mi vida - José María Heredia realismo estético - literatura comprometida

Recibido: $\quad$ agosto 2016

Aceptado: $\quad$ mayo 2017

1] • Revista Iberoamericana, Vol. LXXXV, Núm. 269, Octubre-Diciembre 2019, 1205-1222 